IJMS 17 (2), 165-182 (2010)

\title{
HUMAN RESOURCE RETENTION PRACTICES FROM THE FACULTY'S PERSPECTIVE: CASE FOR A PRIVATE UNIVERSITY IN BANGLADESH
}

\author{
MOHAMMAD A. ASHRAF \\ MOHD. H. R. JOARDER \\ School of Business \\ United International University, Bangladesh
}

\begin{abstract}
Human resources and personnel management is one of the burning issues today. Employee retention is thus being considered as one of the core challenges faced by many organisations especially in the private sector of the economy. In this research, a conceptual model was developed and applied in the context of the faculty retention policy of a private university in Bangladesh. The study was conducted in 2008 by collecting 54 data which were employed primarily to evaluate the current human capital retention practices of the university from the faculties' point of view. The research identified the core elements of human resource practices, which strongly influence the decision of faculty members to remain in the organisation. Several statistical analytical techniques such as Factor Analysis, Multiple Regression Analysis, ANOVA, and correlation analyses have been used to measure the level of incentives of the faculties rendered by the concerned university. The result showed that university culture and policies, work environment, teamwork relationship, and challenging opportunities are significantly related with the faculty retention policies practised by the university.
\end{abstract}

Keywords: Human resource management; faculty retention; private university; influencing factors.

\section{Introduction}

Human capital, in today's competitive knowledge-base "flat world" (DiRomualdo, 2006), is measured as one of the key resources for the overall success of the business. In practice, each and every dynamic venture incessantly struggles to get and retain the best talented employees for its organisation (Szamosi, 2006). Following this fact, 
strategic staffing has become a vital issue, because the ability to cling on to highly talented core employees can be critical to the future survival of the business (Ready, Hill \& Conger, 2008). In any event, the loss of core human capital is extremely costly, which accrues in numerous ways such as bidding up of market salaries for experienced hires to replace them, the costs of recruiting and assimilating new talents, the lost-investment in training and development and the hidden costs of lost-productivity, lost-sales opportunities, and strained customers relationships (Goffee \& Jones, 2007). An empirical study revealed that about $80 \%$ of global business leaders believe the human resource management (HRM) as more important today than they were before, and $68 \%$ believe retaining talent is more important than acquiring new blood (Joarder, 2009).

The scarcity as well as job switching of highly qualified people is not only prevalent in private businesses, but also in the higher education sectors particularly in the rapidly expanding private universities in Bangladesh (Joarder, 2009; Haque, 2004). In fact, since the enactment of Private Universities Act of 1992, Bangladesh has seen a tremendous growth in private educational platforms over the recent years mainly through the emergence of a large number of universities in the private sector (Ashraf, 2009). In 2000, the number of these universities was only 17 , but today it has reached a total of 53 (UGC, 2008). For a university, the key human resources are its faculty members, who are also observed to be highly prone to switch their job frequently which is regarded nowadays a major problem for the private universities in Bangladesh (Ashraf, 2009). With little exception, every private university is experiencing a range of 12 to $18 \%$ faculty turnover in Bangladesh (Joarder, 2009). According to Jalil (2009), the turnover rates vary from 16 t0 17\% per year. Hence, in order to sustain and to succeed in this uncertain as well as competitive market environment, a university should be careful in hiring qualified pool of key faculty members and at the same time it should have the strategic decision to retain those talented people for a protracted time period. According to the personnel of the registrar's offices of the private universities, faculty salary and benefit packages, teaching loads, work environment, faculty freedom, and flexibility issues are the main issues of faculty turnover (Joarder, 2009).

In comparison with the private universities, the turnover scenario in the public universities of Bangladesh is different (UGC, 2008). According to the university grant Commission (UGC, 2008), faculty turnover rates in private universities are considerably higher than public universities. With a few exceptions, most of the private universities have been suffering from the lack of own academic 
campus, poor infrastructure, insufficient facilities both for students and faculty members, inadequate highly qualified full-time faculty members, and high dependency on the part-time faculty and instable faculty member movements. Faculty members of the public universities enjoy various kinds of tangible and intangible job benefits and also opportunities of part-time teaching in the private universities for which faculty of public universities, in rare occasions, leave their jobs. The UGC officials highlighted that very few faculty members voluntarily leave public universities and the rate ranges from 1 to $2 \%$, which is considerably lower as compared to that of the private faculty turnovers (Joarder, 2009). Despite this disturbing fact regarding high turnover in private universities of Bangladesh, there is a serious lack of empirical reviews which focus on the causes of this high turnover in private universities' teaching-job market and on the measures of enhancing the retention status of the qualified faculty members.

The prime thrust of this paper is, therefore, to present the human resource (HR) factors and organisational factors separately that most significantly influence key faculty members' decisions to remain employed at a particular organisation. Besides, this study had also developed a conceptual model of faculty retention in the study based on the focuses on HR factors as well as organisational factors, and tested the proposed model in the context of a private university in Bangladesh. Moreover, the study sought to describe the importance of retaining critical faculty members and developing strategies to enhance human capital retention practices. Results of the study, however, are hoped to assist in the development of an effective HR retention policy for other organisations as well.

\section{Literature Review}

A plethora of studies have provided insight in the management of employee retention as a crucial organisational function involving several organisational factors in order for achieving and preserving competitive advantage (Ramlall, 2003; Abbasi \& Hollman, 2000). Retention, as a way of "talent management", is a strategic priority (HR Focus, 2003). Effective retention strategies limit the level of turnover within an organisation from the negative consequences of employee turnover (Hom \& Griffeth, 1995).

Multiple organisational factors may influence employees to join, stay, or leave (Lew, 2009). A study by Bodla and Hameed (2009) identified organisational factors as controllable variables such as working conditions, satisfaction with supervision, organisational commitment, 
and job stress that can influence employee turnover intentions. A number of studies showed that proper organisational and human resource management of an organisation could ensure competitive advantage over others. Goffee and Jones (2007) maintained that for a growing number of companies, competitive advantage lies in the ability to create an economy driven not by cost efficiencies but by ideas and intellectual know-how. These people are the handful of employees whose ideas, knowledge, and skills give them the potential to produce disproportionate value from the resources their organisations make available to them.

The retention of the core faculty is also an equally important issue for any organisations. The performance of organisations in seeking to achieve organisational goals depends on many factors, such as strategy, structure, technology, people retention, and management processes. Lepak and Snell (2002) asserted that highly qualified employees' skills and knowledge are a source of competitive value to the organisation. Since the compensation package is the most important motivational factor for the employees of any organisation, companies often provide various pay packages for their core employees to stay with their organisations. The package includes special pay premiums, stock options or bonuses, incentives, profit sharing, and so on. Thus, there have been several studies that showed compensation package as an important issue for motivating employees and discussed the structure of the pay (Ashraf, Joarder, Al-Masum \& Ibrahim, 2007; Parker \& Wright, 2000).

Selection of a person whose values, norms, and ethics are congruent with those of an organisation is necessary to keep him or her for a long time. Morely (2007) put forward that a high level of personorganisation fit (P-O fit) is related to a number of positive outcomes. $\mathrm{P}-\mathrm{O}$ fit was found to be correlated with work attitudes such as job satisfaction and organisational commitment. P-O fit was also found to predict intention of quit and turnover. So, it can be said that $\mathrm{P}-\mathrm{O}$ fit is a better predictor of key employee retention.

The absolute success of any business organisation greatly depends on the employee performance which can be enhanced only through proper training. Training is considered the most effective weapon to develop human resource that help them cope with the changing environment. Wetland (2003) stated that training is often needed when new employees are appointed, promoted, and transferred, and also when policies of the organisation are changed and new assignments are given to them. Employees are expected likely to acquire new skills and knowledge, apply them on the job, and share them with other 
employees. By and large, employees want good training opportunities to increase their human capital that results in higher market values. Nowadays, companies are finding that the more training employees get, the more likely they are to stay.

A substantial number of studies found that challenging opportunity is one of the important reasons for which employees choose to leave the organisation. Lack of challenge and opportunities in one's position, and the inability to advance in one's career were the most significant factors (Accenture, 2001). Providing the organisation with challenging assignments with well-defined performance measures and feedback is important for a high performance environment in which key employees can achieve their personal objectives (Furnham, 2002). People want a job with wide-ranging responsibilities and a lot of task-varieties, because they want to have more job skills lest they are forced to get out of the company and go for another job (Jardine \& Amig, 2001).

People often join a company or seek employment within a particular industry, because they find its culture appealing. Since people join an organisation partly because they are attracted to the culture and structure, this is where retention management begins. Research has shown that key employees' retention depends on organisation culture and policies. Corporate culture is described as the invisible force that encourages key players to exist in a business organisation, especially in Asia (Denison, Haaland \& Goelzer, 2004). Moreover, management philosophy and style, communications protocol, and policies are also significant parameters to influence the key people to work for a particular organisation which create the uniqueness of each company (Furnham, 2002). Hence, it is suggested that a positive link between strong organisational culture and qualified employees' commitment exists.

Team cohesion is the binding force of the mosaic of an organisation. Core working members work for a long time for an organisation when they have strong relationships with their colleagues (Clarke, 2001). Organisations today encourage project assignments to involve work with peers, and opportunities for social interaction both on and off the job (Marchington, 2000). Employees who work within a team are more likely to feel an increased commitment to the work-unit's efforts and the organisation as a whole. Consequently, talented employees tend to remain in organisations due to the strong teamwork relationships that they have established at the workplace (Clarke, 2001; Marchington, 2000). 
People like a friendly place to work. The friendly-factor does not require a large investment and expense, but it does require time and thoughtful consideration. For example, many companies are providing flexible working schedules in work arrangements and are experimenting with other ways to help individuals manage their work and personal life issues (Perry-Smith \& Blum, 2000). Several studies done by Hamphrey, Morgesen, and Mannor (2009), and Gibson, Cooper, and Conger (2009) found that key team players would stay with a company that clearly considers and cares for their priorities and problems, and give importance to his or her personal and family lives.

\section{Research Methodology}

A structured questionnaire was used in the survey. The respondents (faculty members) were asked to what degree the faculty retention policies practised by the university corresponded to their expectations on the 48 items related to eight factors of employee retention model. The variable of faculty retention constitutes six items which are provided in Table 3. The questionnaire was sent to 60 full-time faculty members of a private university located in Dhaka, of which 54 faculty members responded resulting in a $90 \%$ participation rate. The survey was initiated to cover some other private universities in Dhaka, but the authorities of those universities did not permit any survey in their universities. So the authors were compelled to limit the data collection process only within one university which employees serve as fulltime faculty members. For this reason, convenience sampling method was followed for collecting data. The study used a seven point Likert scale with closed ended questions ranging from "strongly agree" to "strongly disagree". The researcher assigned numeric values to those options ranging from 7 to 1 . A total of 48 questions were asked for this survey.

The statistical package for social science (SPSS, Version 14) was used to analyse the quantitative data. The reliability test was conducted to verify the internal consistency of the variables obtained in the sample. The overall Cronbach's alpha value of all eight variables was 0.8982 , which is much higher than the minimum acceptable level suggested by Nunnally (1978). Besides the overall alpha value, alpha values for all individual variables were also calculated and those are represented in Table 1. Several statistical analytical techniques such as Factor Analysis, Multiple Regression Analysis, ANOVA, and correlation analysis were used to measure the level of incentives of the faculties rendered by the concerned university. 


\section{Conceptual Framework}

This study investigated the factors affecting employee retention of the measured variables and the cause and effect relationship of among the variables. Four HR factors and four organisational factors have been identified which affect the employee retention. The HR factors comprises compensation package, person organisation fit, challenging opportunity, and training and development. The organisational factors included in the framework are working environment, company culture and policy, leadership behaviour, and teamwork relationship.

Compensation package is the most important motivational factor for the employees in the context of Bangladeshi organisations. Companies often provide various pay packages for their employees to stay in the organisation. These include special pay premiums, stock options or bonuses, incentives, profit sharing, etc. Thus, it can be said that the compensation package has a strong influence on employee retention. Person-organisation (P-O) fit means whose values, norms and ethics are congruent with those of an organisation is necessary to keep him or her for a long time in the organisation. Evidence says that a high level of P-O fit is related to a number of positive outcomes. So, it can be said that $\mathrm{P}-\mathrm{O}$ fit is a better predictor of employee retention (Figure $1)$.

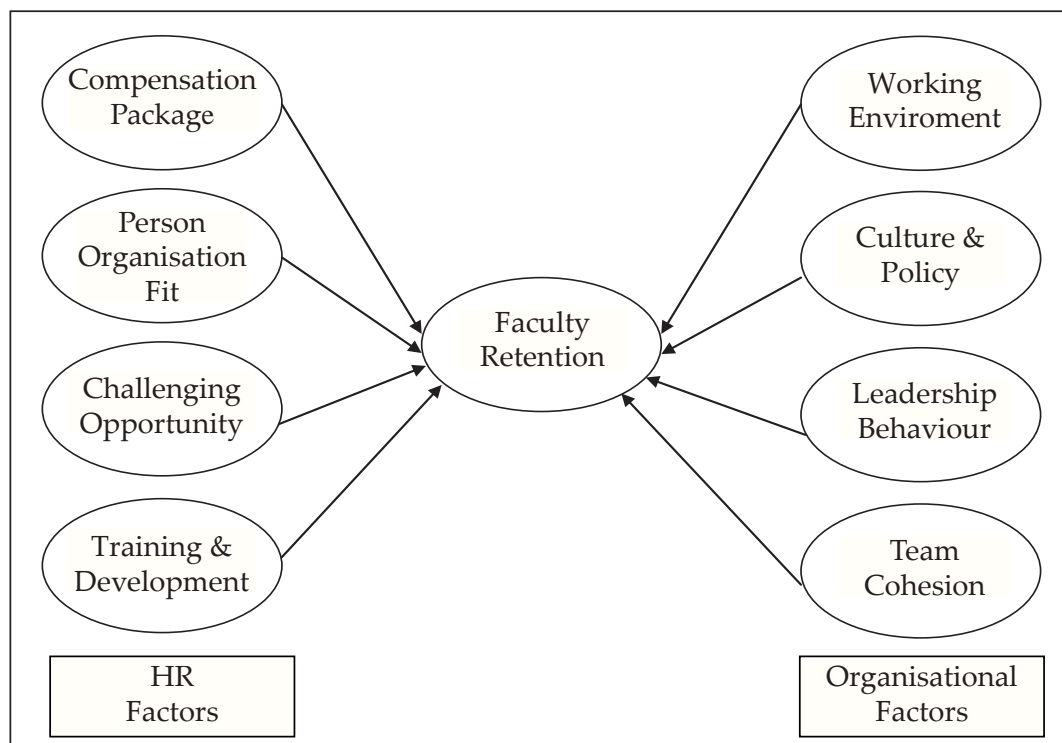

Figure 1. Conceptual model for key faculty retention policy of an educational organisation. 
Challenging opportunity is considered to be one of the important reasons employees would choose to leave or stay in the organisation. Challenging projects and their results are important for a high performance job market milieu in which employees can achieve their personal goals and career objectives. Training and development is another dimension that employees care for in to be dynamic and competent in the job market. Hence, more training and developmental tasks motivate the employees to stay longer in the company.

Among the organisational factors, working environment is the most important variable. People like a friendly place to work. The friendly-factor does not require a large investment and expense, but it does require time and thoughtful consideration. Evidence suggests that employees will stay with a company that clearly considers and cares for their priorities and problems, and give importance to his or her personal and family life. Attractive company culture and policy attract employees more to come and join the company. So this is the starting point of retention management. Empirical research showed that employees' retention depends on corporate culture and policies. So, it is postulated that there is a positive link between strong organisational cultures and employee retention practices.

Leaders are mentors who can direct workers in the right direction. In this way, leadership enhances organisational commitment. Thus, it appears that leadership behaviour has a positive influence on turnover intention of team members in the organisation. Organisations today encourage team building and group oriented projects that enhance chances for more socialisation, both on and off the job. Teamwork increases commitment to the work unit's efforts and provides integrated building blocks to the organisation. Hence, employees have a propensity to stay in organisations for the strong teamwork relationship they have established at the workplace.

\section{Data Analysis and Interpretations}

\section{Principal Factor Analyses}

Tables 1 and 2 represent the principal factor analyses, which have been tabulated separately with the respective loaded values of organisational and HR factors respectively. Both tables provide the Cronbach's alpha values for each corresponding factors. Nunnally (1978) suggested that the reliability range from 0.50 to 0.60 is acceptable. In this study, most of the variables except one exhibit 
the reliability value less than .70 . The tables show only independent factors whose eigenvalues are greater than one. These eight factors account for $66.71 \%$ of the variance in the data on attitudes toward core faculty retention.

In Table 1, university culture and policies are exhibited as the most important factor that contains more information than any of the other factors, loaded with the eigenvalue of 13.80 . This factor alone explains $28.75 \%$ of variance, which indicates that it provides the maximum insights of talented faculty retention practices of the university. Hence, the policy makers of this organisation ought to enhance friendly culture and policies in order to retain their key faculty members. The second most important factor here is the working environment. Working environment itself explains 7.081\% variance of the dependent variable of key faculty retention. So, the organisation must promote homely working environment for their key faculty members to keep their valued service for the long time, which is the ultimate target for a dynamic organisation. The two other organisational factors for the study were leadership behaviour and teamwork cohesion, which constitute eigenvalues of 2.859 and 2.255 respectively. The two factors altogether account for $10.65 \%$ of variance in the data attitudes toward scholar faculty retention. These two factors also need to be addressed by the organisation for retaining valuable faculty member in the organisation (Table 1).

In Table 2, the HR factors are included. The most important factor here in this category is challenging opportunity that explains $8.45 \%$ of variance with the eigenvalue of 4.057 . Thus, every dynamic organisation should develop strong HR department and the HR personnel should continuously search for duties and responsibilities, which are more appealing for their faculty members and assign it as per their respective positions, i.e. right people for the right position of teaching. The second most important HR factor is training and development and this factor accounts for $4.46 \%$ of variability in the data. Through training and development, a faculty member can develop his or her skills and knowledge and hence can give more efficient output to the organisation. So this HR factor also demands notable attention to make the organisation more dynamic and efficient. The other two HR factors were P-O fit and compensation package. These two factors together clarify $7.299 \%$ of variance in the data. An effective team management must select the right people for the right position and offer them with the best compensation package so that they will be motivated and loyal to their faculty (Table 2). 


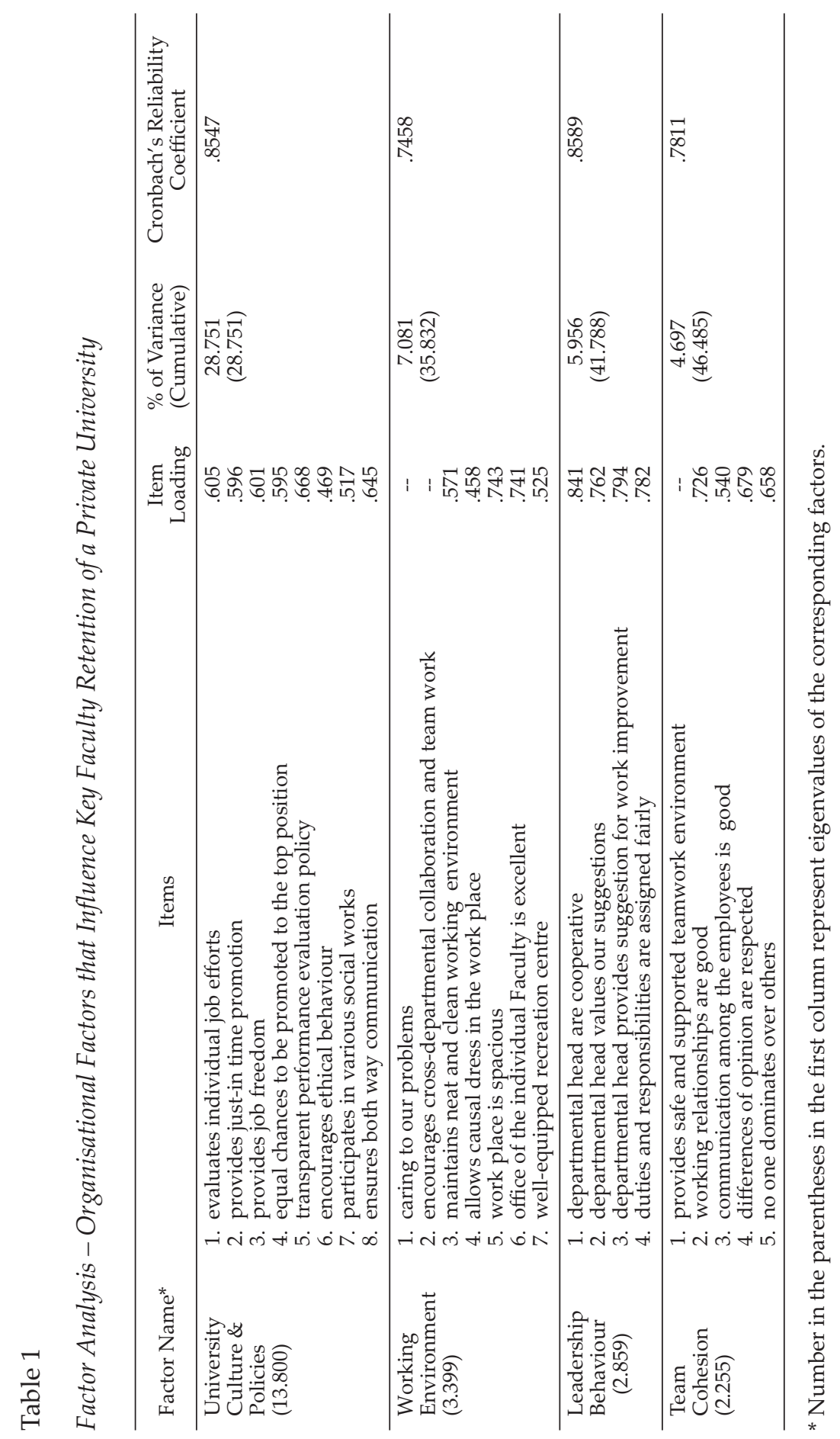

174 IJMS 17 (2), 165-182 (2010) 


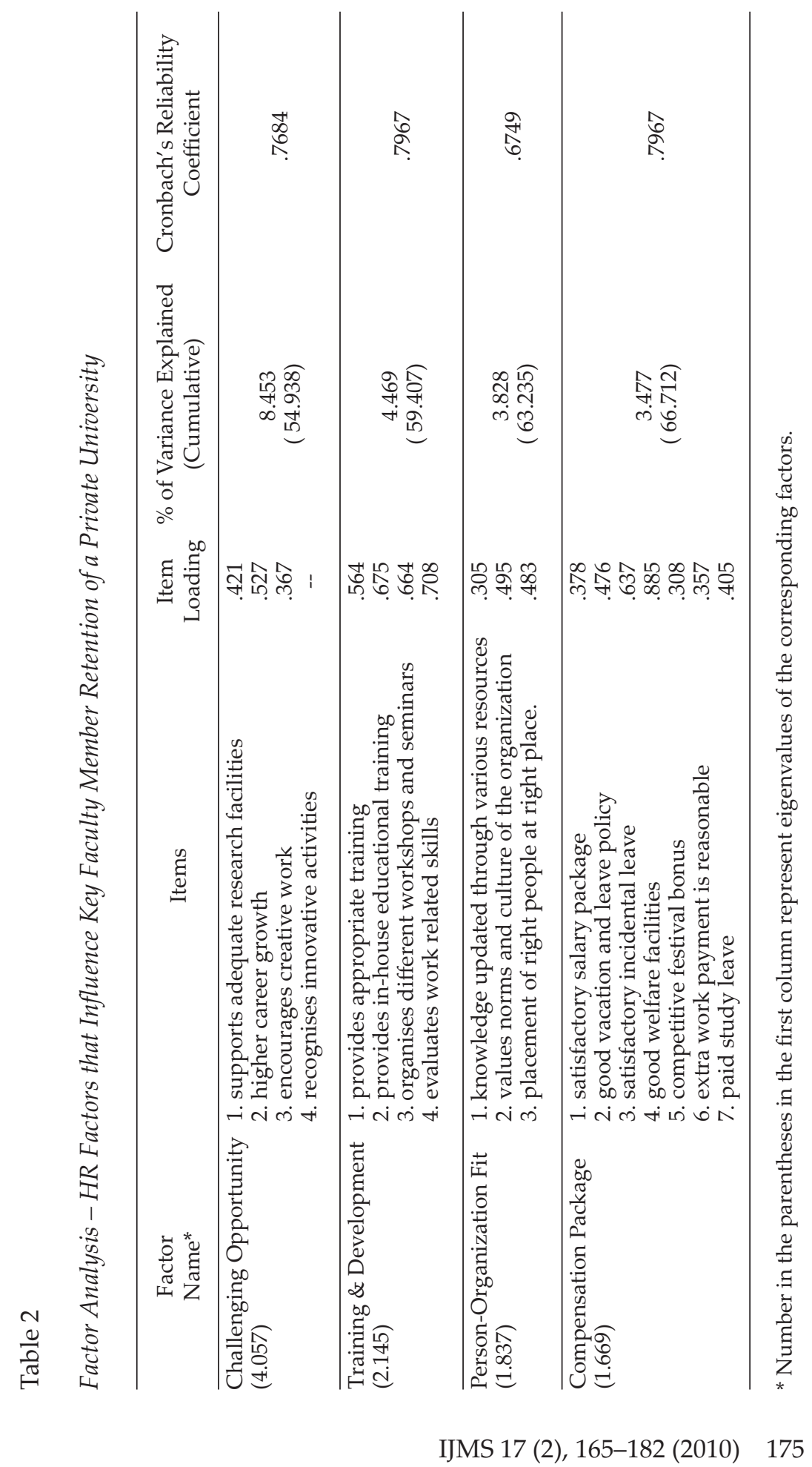


In Table 3, the dependent variable of faculty member retention including items, item loadings, and Chronbach's reliability coefficient are presented. The item loadings and the value of reliability coefficient are quite high. This means that the study-reliability is considerably high and the overall output for retaining the faculty members of the university deserves merit for revising the faculty retention policy of the university.

Table 3

Factor Analysis - Items, Loadings and Chronbach's Alpha Value of Faculty Member Retention as Dependent Variable

\begin{tabular}{llcc}
\hline $\begin{array}{c}\text { Dependent } \\
\text { Variable }\end{array}$ & \multicolumn{1}{c}{ Items } & $\begin{array}{c}\text { Item } \\
\text { Loadings }\end{array}$ & $\begin{array}{c}\text { Chronbach's } \\
\text { Reliability } \\
\text { Coefficient }\end{array}$ \\
\hline $\begin{array}{l}\text { Faculty } \\
\text { Retention } \\
\text { (FR) }\end{array}$ & $\begin{array}{l}\text { 1. every faculty member will not leave } \\
\text { if similar job is offered }\end{array}$ & .580 & .8616 \\
& $\begin{array}{l}\text { 2. every faculty member feels homely } \\
\text { 3. every faculty member is satisfied } \\
\text { with job }\end{array}$ & .622 & \\
& $\begin{array}{l}\text { 4. every faculty member is proud to } \\
\text { work for this university }\end{array}$ & .690 & \\
& $\begin{array}{l}\text { 5. job status of the university is } \\
\text { socially recognised }\end{array}$ & .630 & \\
& $\begin{array}{l}\text { 6. every faculty member upholds the } \\
\text { interest of the university }\end{array}$ & & \\
\hline
\end{tabular}

\section{Descriptive Statistics and Correlation Analysis}

The mean scores computed in Table 4 are based on the weighted average method. In the seven-point scale, these mean values represent a somewhat positive level of faculty member retention practices from the point of view of the entire team members of the university. Among all the factors, the leadership behaviour has the highest mean value of $6.088(ð=0.961)$. This means faculty members are highly satisfied with that practice factor by the university and it is well accepted by all the faculty team members. A notable point is that despite the higher mean value, leadership behaviour has no significant correlation with key faculty member retention. This might be due to the lack of sufficiently large number of samples undertaken in the study. From the characteristics of the data, it is observed that the data of training and development $(\mu=4.273, \delta=1.118)$ and P-O fit $(\mu=4.746, \delta=1.077)$ are highly deviated from the mean among all other factors. This statistical evidence implies that these two factors involved in the practice of the university are not adequately designed for all the faculty members. Thus, the university should revise their 
training and development practices, and selection policy. On the other hand, the data of working environment $(\mu=5.574, \delta=.8387)$ and teamwork cohesion $(\mu=5.618, \gamma=.8450)$ have been found to be less deviated from the mean. This statistic indicates that the university has been successfully maintaining a good working environment and encourages teamwork cohesion which are appreciated by all levels of the faculty positions.

In the same table, a significant positive and strong correlation was found for the key faculty retention in relationship with university culture and policy $(\mathrm{r}=.685, \mathrm{p}<.05)$, with challenging opportunity $(\mathrm{r}=.629, \mathrm{p}<.05)$, working environment $(\mathrm{r}=.584, \mathrm{p}<.05)$, person organization fit $(\mathrm{r}=.520, \mathrm{p}<.05)$, and also with teamwork cohesion $(\mathrm{r}=.494, \mathrm{p}<.05)$. These significant correlations indicate that these factors have a strong influence on key faculty member retention policy of the university. Moreover, a positive and strong correlation was found among university culture and policy, challenging opportunity, and P-O fit, which implies that the university should develop and adopt a policy that has complete synchronisation among those factors.

\section{Multiple Regression Analysis}

In the analysis, simple regression technique was used. Key faculty member retention and eight orthogonal component factors were taken as dependent and independent variables respectively. Results are shown in Table 5. In this table, all the variables are shown with their respective regression coefficients (bs) and computed student's t statistics along with their respective significance level. Results of the regression analysis revealed that out of eight control variables, four variables namely university culture and policy, working environment, challenging opportunity, and team-member cohesion had statistically significant effects on the rating of attitude toward the faculty's job retention of the concerned university of this study. The four other variables have no significant impact on faculty member retention. The results related to significant variables are also consistent with the results found in the factor analyses. Among the four significant variables, university culture and policy is significant at $\mathrm{p}<.001$ level, which emphasises that this variable needs special consideration when retaining faculty members in the university. The second most important variable is the working environment, which is significant at $p<.01$ level. So in order for retaining key faculty members in the university, this variable is also very important. The other two variables, namely challenging opportunity and team cohesion, are significant at $\mathrm{p}<.1$ level which focus moderate importance to consider for faculty retention policy. 


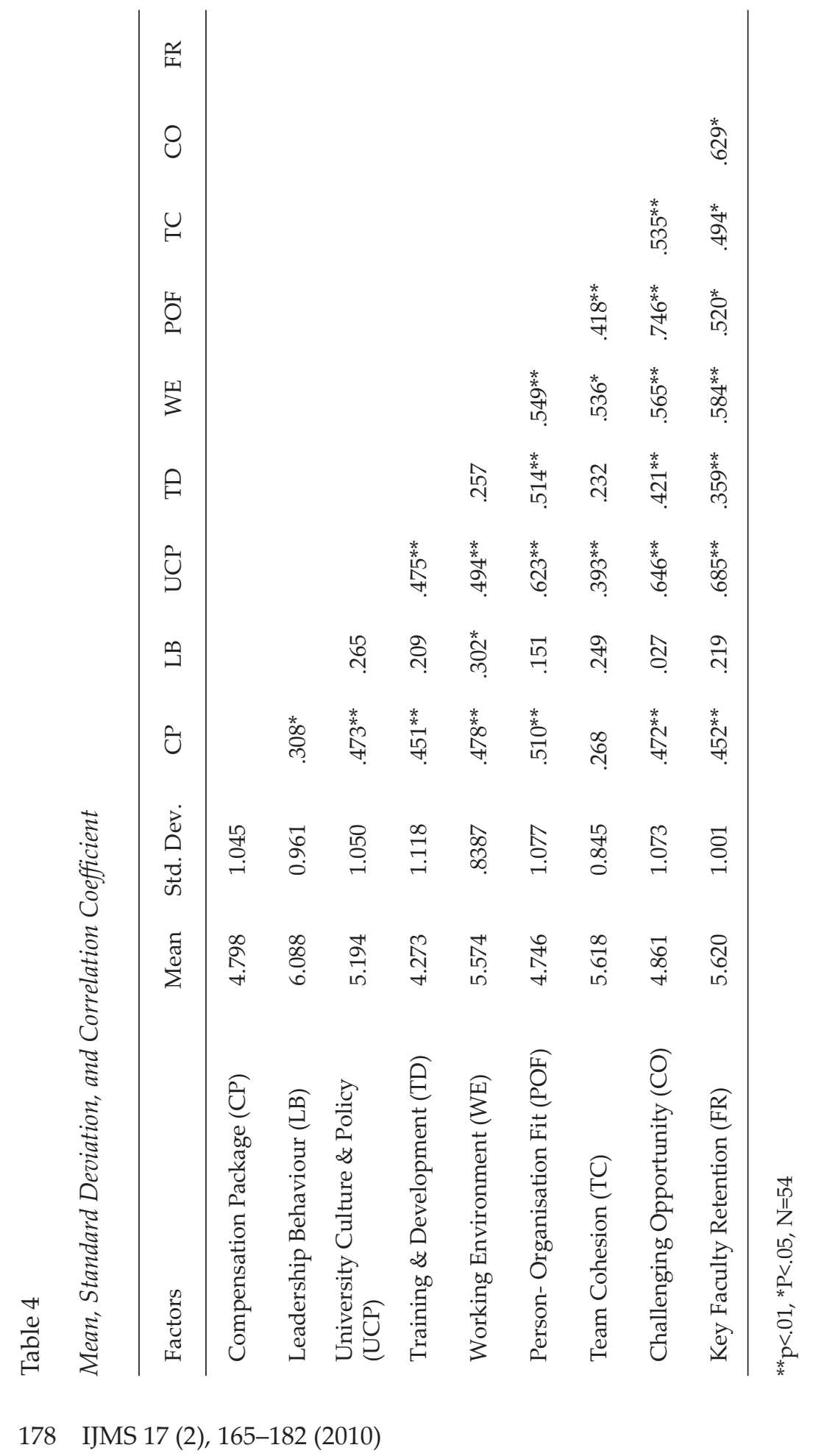


Table 5

Results of Multiple Regression Analysis for Faculty Retention

\begin{tabular}{lcc}
\hline Dependent Variables & Coefficients & t-statistics \\
\hline University Culture \& Policy & .500 & $4.847^{* * *}$ \\
Working Environment & .388 & $3.003^{* *}$ \\
Challenging Opportunity & .213 & $1.629+$ \\
Team Cohesion & .164 & $1.468+$ \\
Compensation Package & .008 & .062 \\
Leadership Behaviour & .016 & .153 \\
Training and Development & .044 & .374 \\
Person Organisation-Fit & .011 & .072 \\
Constant & .861 & \\
$\mathrm{R}^{2}$ & .549 & \\
Adjusted $\mathrm{R}^{2}$ & .531 & \\
$\mathrm{~F}$ & $31.003^{* * *}$ & \\
$\mathrm{~N}$ & 54 & \\
\hline
\end{tabular}

${ }^{* * *} \mathrm{p}<0.001,{ }^{* *} \mathrm{p}<0.01,{ }^{*} \mathrm{p}<0.05,+\mathrm{p}<0.1, \mathrm{n}=54$, Faculty Retention=Dependent Variable

The coefficients of different variables are evident in the above estimated regression equation. Simple regression indicates the calculated value for $R^{2}=0.549$, which means that the eight independent variables in the regression equation together explain $54.9 \%$ of the variation in the dependent variable, namely key faculty retention. The value for adjusted $R^{2}=0.531$ is the value of the co-efficient of determination adjusted for degree of freedom. It states that when adjusted for degree of freedom, the eight independent variables explain $53.1 \%$ of the variation in the dependent variable.

\section{Limitations of the Study}

This research has some weaknesses. Firstly, the study was done for a single private university in Dhaka City of Bangladesh, where more than 50 private universities are located. In fact, the survey was initiated to cover many more universities in Dhaka City, but the authorities of those concerned universities did not give permission to do so. So, there was no choice other than to limit the study to a 
single university. Secondly, the sample size is also relatively small. This is because the total number of full-time faculty member of this university were about 60 , where 54 of them responded and provided data. Nevertheless, the results of this study may improved if the sample size could be increased by bringing in more universities under the survey, but these limitations inherent in this study were thus factually unavoidable. Still the results of the study could be used by the private universities at large in order to improve the faculty member retention policy which may help to reduce the turnover cost of the university.

\section{Conclusion}

The finding of this study suggests that the key faculty member retention of a private university in Bangladesh significantly depends upon four of the eight factors, such as university culture and policies, working environment, challenging opportunity, as well as team cohesion. The remaining four factors, which are compensation package, training and development, person-organisation fit, and effective team leadership behaviour do not have a significant impact on the retention of the faculty members of a private university. Clearly, there is a need for greater analysis of the factors identified. Hence, a better understanding of the interrelationships among these variables would serve to illuminate and provide further insight for academics and practitioners. Further testing of the model in other industries, and over a long period of time would be beneficial. This study only examined the private education sector. Future research will need to confirm to what degree the association between retention and the identified factors does exist for other industries. In conclusion, this study has gone a substantial way toward meeting its own objectives. Still, it has a lot of scope for improvement.

\section{Reference}

Abbasi, S., \& Hollman, K. (2000). Turnover: The real bottom-line. Public Personnel management, 29, 333-342.

Accenture (2001). The high performance workforce: Separating the digital economy's winners from losers. The Battle for Retention Accenture's Study, 1-5.

Ashraf, M. A., Joarder, M. H. R., Al-Masum, R., \& Ibrahim, Y. (2007). Quality management and cost of education at private universities: Case for Bangladesh. Paper presented in $5^{\text {th }}$ ASEAN Symposium held in Kuala Lumpur, Malaysia on 25-27 ${ }^{\text {th }}$ August.

180 IJMS 17 (2), 165-182 (2010) 
Ashraf, M. (2009, March). Faculty shifting at private universities in Bangladesh: Blessing or bane. The Independent, 25, 7.

Bodla, M. A., \& Hameed, A. (2009). Factors affecting employee turnover intentions: Empirical evidence from textile sector of Pakistan. International Journal of Knowledge, Culture and Change Management, 9, 53-64.

Clarke, K. F. (2001). What businesses are doing to attract and retain employee-becoming an employer of choice. Employee Benefits Journal, March, 34-37.

Denison, D. R., Haaland, S., \& Goelzer, P. (2004). Corporate culture and organisational effectiveness. Organisational Dynamics, 33, 98-109.

DiRomualdo, T. (2006). Seven talent management practices that matter. WTN News, April 12.

Furnham, A. (2002). Work in 2020 prognostications about the world of work 20 years into the millennium. Journal of Managerial Psychology, 15, 242-250.

Gibson, C. B., Cooper, C. D., \& Conger, J. A. (2009). Do you see what we see? The complex effects of perceptual distance between leaders and teams. Journal of Applied Psychology, 94(1), 62-76.

Goffe, R., \& Jones, G. (2007). How to manage the most talented. Harvard Business Review, 85, 70-71.

Haque, M. S. (2004). Quality management issues in business education in Bangladesh: A synoptic review based on a Canadian and European papers. Management Forum 2004, Published by Association of Management Development Institutions of Bangladesh (AMDIB), Institute of Business Administration (IBA), University of Dhaka, Bangladesh.

Hamphrey, S., Morgesen, F. P., \& Mannor, M. J. (2009). Developing a theory of the strategic core of teams: A role composition model of team performance. Journal of Applied Psychology, 94, 48-61.

Hom, P. W., \& Griffeth, R. W. (1995). Employee turnover. Cincinanti Ohio: South Western College Publishing.

(2003). Rewards: The not-so-secret ingredient for managing talent. HR Focus, 80, 3-5.

Jalil, M. B. (2009, December). Improving human resource management in private universities. The New Nation, 27, 11.

Jardine, E., \& Amig, S. (2001). Managing human capital. Behavioural Health Management, 21, 25-31.

Joarder, M. H. R. (2009, November). Faculty turnover rate: The critical issue for private Universities in Bangladesh. Unilife, 1, 30-31.

Lepak, D. P., \& Snell, S. A. (2002). Examining the human resource architecture: The relationships among human capital, employment, and human resource configurations. Journal of Management, 28, 517-543. 
Lew, T. (2009). The relationships between perceived organisational support, felt obligation, affective organisational commitment, and turnover intention of academics working with private higher educational institutions in Malaysia. European Journal of Social Sciences, 9, 72-87.

Marchington, M. (2000). Teamworking and employee involvement: Terminology evaluation and context in team working. Basingstoke: Macmillan.

Morley, M. J. (2007). Person organization fit. Journal of Managerial Psychology, 22, 109-117.

Nunnally, J. C. (1978). Psychometric theory. New York: McGraw-Hill.

Parker, O., \& Wright, L. (2000). Pay and employee commitment: The missing link. Ivey Business Journal, 65, 70-79.

Perry-Smith, J., \& Blum, T. C. (2000). Work family human resource bundles and perceived organizational performance. Academy of Management Journal, 43, 1107-12.

Ramlall, S. (2003). Managing employee retention as a strategy for increasing organisational competitiveness. Applied HRM Research, 8, 63-72.

Ready, D. A., Hill, L. A., \& Conger, J. A. (2008). Winning the race for talent in emerging markets. Harvard Business Review, 86, 72-79.

Szamosi, L. T. (2006). Just what are tomorrow's SME employees looking for? Education and Training, 48, 654-665.

UGC (2008). University Grant Commission (UGC) Profile. Dhaka: UGC.

Wentland, D. (2003). The strategic training of employees model: Balancing organisational constraints and training content. SAM. Advanced Management Journal, 68. 